\title{
An Interactive Mobile Lecturing Tool for Empowering Distance Learners
}

\author{
http://dx.doi.org/10.3991/ijim.v7i4.3175 \\ O. Boyinbode and D. Ng'ambi \\ University of Cape Town, Cape Town, South Africa
}

\begin{abstract}
-face-to-face learning is most prominent in higher education in developing countries of Africa, where learning is teacher-centred; this type of learning does not promote deep learning. Vodcasts and podcasts are increasingly becoming popular in higher education as a means of enhancing learning especially for part-time students who are separated by distance from their teacher; this mode of teaching is known to entertain some limitations. In this paper we report on MOBLEC, an interactive Mobile lecturing model that removes the limitations of podcasting or vodcasting model and promote deep learning. This model enables students to comment on lecture vodcasts using mobile devices, and aggregated comments become an educational resource. The model was evaluated at the Bindura University of Science Education (BUSE), Zimbabwe. The paper describes an interactive mobile lecturing tool for empowering learners that are separated from their teachers and the evaluation results from BUSE, Zimbabwe.
\end{abstract}

Index Terms-Deep learning, Mobile devices, Mobile Learning, Mobile lecturing, Lecture vodcast

\section{INTRODUCTION}

Some Higher Educational Institutions (HEIs) in developing countries of Africa enroll students who are full-time and part-time students. In these HEIs the part-time students are mostly distance learners [2]. Full-time students are always on campus throughout the year to receive instruction from teachers and sit for examinations, while part-time students may visit the campus few times in a year to receive instruction and then sit for examinations with their full-time student counterparts who had been steadily receiving instructions throughout the year. The consequence of this limitation is poor academic performance. Some HEIs use podcasting or vodcasting as a way of improving distance learning for their students [7]. A podcast is a collection of digital media files (audio) distributed over the internet using Really Simple Syndication (RSS) technology or Atom feeds. A vodcast is a video podcast. Podcast or vodcast has emerged as a tool for mobile learning where students download lecture vodcast to their mobile devices and learn on the move [3]. Lecture vodcast or podcast and face-to-face lecture have one way communication (unidirectional) though podcasts still have the advantage that learners can re-listen to recorded lectures and take down notes, this one-way interaction is limited to actively engage students in deep learning. Deep learning is a form of learning where learners extract meaning and understanding from lecture materials [11]. Students cannot interact by asking questions or get access to other peer's ideas which are critical to foster deep learning. Mobile learning (M-learning) enables students to watch recorded lectures at their own convenience and pace. Podcasts and vodcasts have emerged as one of the tools aiding this trend [8]. Recording lectures as vodcasts and making these available on mobile devices through an interactive mobile learning tool (mobile lecturing) may help students to engage in high-level interactions. In Podcasting or Vodcasting, students cannot interact by asking questions or get access to other peer's ideas which are critical to foster deep learning. This paper explores ways in which mobile lecturing can engage distance learners in learning to foster deep learning. This paper also presents an interactive mobile lecturing model "MOBLEC" that allows students to interact with lecture vodcasts on their mobile devices in a bidirectional interaction overcoming the limitation of unidirectional interaction inherent in lecture podcast or vodcast. Section 2 explains differences between mobile lecturing and mobile learning. Section 3 describes an interactive mobile lecturing model " MOBLEC" and "Mobiles tool". Section 4 describes the evaluation result obtained from the Bindura University of Science Education; Zimbabwe Section 5 presents the conclusion.

\section{MOBILE LEARNING AND MOBILE LECTURING}

Mobile devices are devices that can be used to access information and learning materials from anywhere and at any time at the learner's convenience [5]. Mobile learning can be defined as "any sort of learning that happens when the learner is not at a fixed, predetermined location or learning that occurs when the learner takes advantage of the learning opportunities offered by mobile technologies" [9]. Mobile learning does not have to take place in a fixed location, such as a classroom, or within a specified time, instead learning can occur in any locations and at any time [10]. Students learn on the move with their mobile devices at any time and any place, the role of the teacher in the $\mathrm{m}$ learning experiences has remained minimal and the learning unevaluated. Mobile learning in this paper is defined as a type of learning that allows students to engage and learn with mobile technologies when they are on the move with minimal or no involvement of the teacher while mobile lecturing is defined as a form of learning in which students engage in high-level interactions with lecture vodcasts on their mobile devices to enhance their learning with the teacher specifying the learning tasks to trigger deep learning [3]. Warburton [11] defines deep learning as a form of learning where students construct meaning and understanding from learning materials and experiences. He further indicated that deep learning is dependent on a student's level of engagement with the learning content thus teachers must be able to provide an environment where students develop a strong 
personal interest in learning. Anderson [1] indicates that "Deep and meaningful formal learning is supported as long as one of the three forms of interaction (student to teacher; student to student; student to content) is at a highlevel". In this paper we define deep learning as a learning which occurs when distance learners construct meaning and understanding from learning resources and experiences through high-level interactions

\section{MOBLEC: AN INTERACTIVE MOBILE LECTURING MODEL}

MOBLEC model employs mobile lecturing to foster deep learning through students' high-level engagement with lecture vodcasts on their mobile devices. The MOBLEC model [3] is shown in Figure 1.

Device usability (AB): The Device Usability (AB) contains attributes that are common to both the mobile device (A) and learner (B) aspects. Mobile devices' portability, intuitiveness and ability to provide "anytime and anywhere" access to information help to characterize their affordances. This intersection relates characteristics of mobile devices to learning tasks such as the acquisition of knowledge as well as the manipulation and storage of learning processes. These processes are affected by how intuitive the device is or how quickly a learner can begin to understand the device.

Interaction technology (AC): Mobile device (A) and Interaction $(\mathrm{C})$ aspects form the basis of the interaction technology intersection. This intersection refers to the ability of learners to interact with each other; it describes how mobile devices enable interaction and collaboration. Here, the software tools provided by mobile technologies for interaction constitute the interaction technology. These tools allow learners to interact in groups where they can acquire information and share knowledge. Mobile devices have networking mechanisms for connecting to the interaction tools i.e. Wi-Fi, 3G networks etc. It describes the affordances of mobile devices to engage in high-level interactions. It defines a mobile lecturing tool (See figure 2) to enhance interaction in the MOBLEC model.

Learning Engagement (BC): Learner (B) and Interaction $(\mathrm{C})$ aspects forms the basis of the learning engagement intersection. It focuses on the learning interactions (Anderson interactions: Student-to-Content, Student-toStudent, Student-to-Teacher (Anderson, 2003)) that are enabled by the interaction technology. Usually these interactions will be driven by a learning task or a desire to know something or consult with the knowledgeable others, etc.

All three aspects overlap at the primary intersection (ABC) which is located in the centre of the Venn diagram. The primary intersection, a combination of all three aspects, represents and defines the mobile lecturing process. In this model mobile lecturing enables students to engage in high-level interactions with lecture vodcasts on their mobile devices to foster deep learning. High-level interactions here involve interactions using Anderson's educational interactions. The next section describes MOBILect, an interactive mobile lecturing tool for evaluating the MOBLEC model.

\section{A. An Interactive Mobile Lecturing Tool (MOBILect)}

The interaction technology (AC) of MOBLEC model [3] defines a mobile lecturing tool to enhance 'interaction'
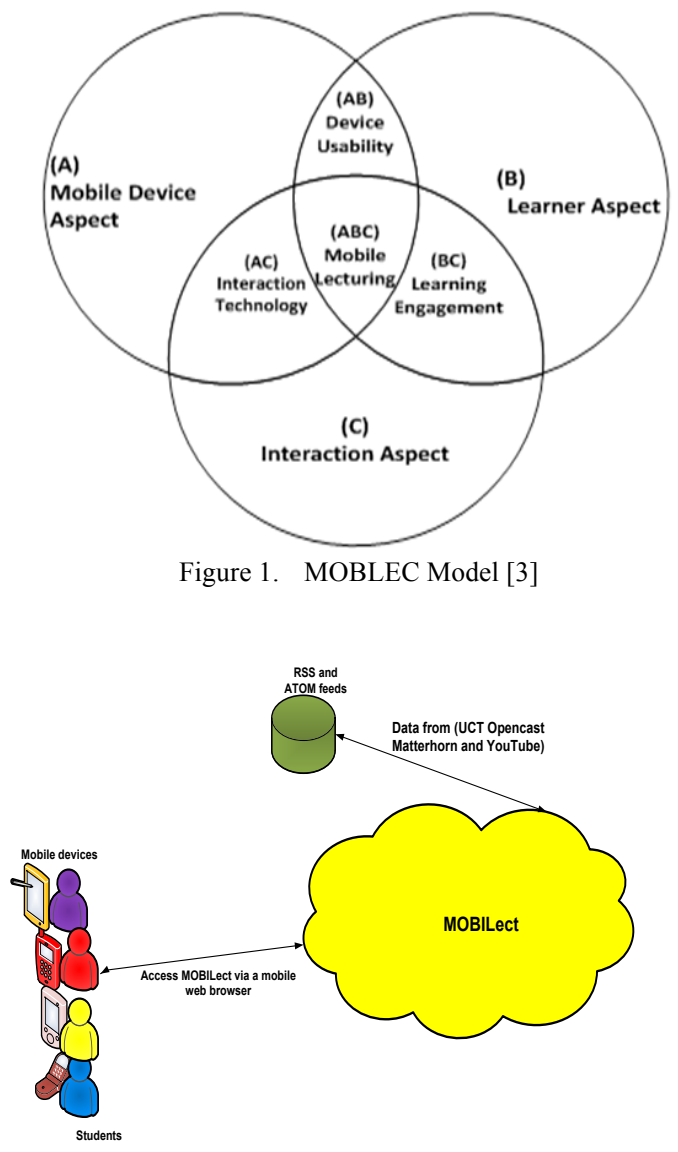

Figure 2. Architecture of MOBILect [3]

in the model. Figure 2 describe the architecture of this mobile lecturing tool "MOBILect" (an interactive mobile lecturing tool).

Mobile Devices: Students access MOBILect via mobile web browsers. These provide interfacing for the students. Mobile devices display images of videos and audios accessed from MOBILect. MOBILect is a web-based Html5 application [3].

\section{Methodology}

This section describes the research method for the procedure for data collection and analysis. Details of the methodology are described in the following sequence: Case Study, Evaluation, Analysis of students' comments and Analysis of open-ended questions.

\section{A. Case Study}

The Case Study was Bindura University of Science Education (BUSE), Zimbabwe. BUSE is one of higher education institutions (HEIs) in developing countries of Africa; the course evaluated was titled "Introduction to Computer Programming module (CS111)" in the Department of Computer Science. This course was chosen because the course has been recorded by Cam studio by the lecturer and was simply uploaded to MOBILect. Cam Studio (see figure 3), an open-source software is used to record the computer screen, while including audio input [4]. Cam Studio is capable of recording all screen activities that happen on the computer. The need for MOBILect for part- time students at Bindura University stems from the difference in learning structure between 


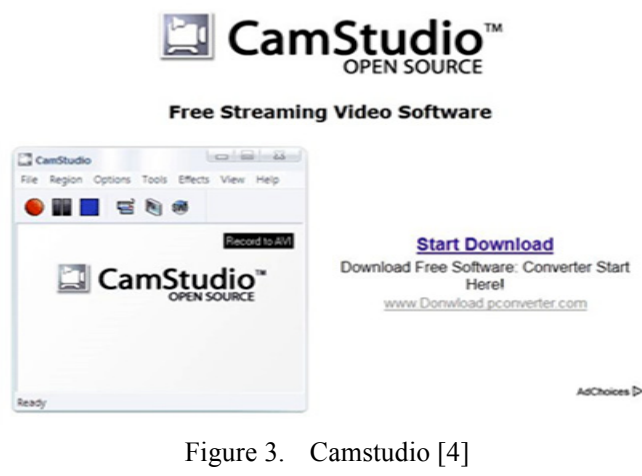

full-time students and part-time students in the institution. Full-time students are always on campus throughout the year to receive instruction from teachers and sit for examinations. The part-time students visit the campus only few times in a year to receive instruction and then sit for examinations with their full-time student counterparts who had been steadily receiving instructions throughout the year. The part-time students are dispersed all over Zimbabwe and are employed, hence are engaged in parttime studies. They visit the campus only four times in a year to receive instruction. The consequence of this limitation is poor academic output. MOBILect was adopted to assist these part-time students to interact with the lecture vodcast on MOBILect to enhance their learning and foster deep learning.

\section{B. Participant Selection}

For the purpose of evaluation at Bindura University of Science Education, Zimbabwe, CS 111 titled Introduction to Computer Programming was evaluated. Part-time students were invited to use the MOBILect by their lecturer. The total number of part-time students enrolled for the courses were fifteen students. Five students responded and evaluated MOBILect. They were four females and one male. The students signed a consent form acknowledging their willingness to take part in the exercise. The CS 111 lecture vodcast was loaded into MOBILect.

\section{Procedure for Evaluation}

Five students took part and accessed MOBILect from different places at different time using their personal mobile devices via $\mathrm{Wi}-\mathrm{Fi}$ and $3 \mathrm{G}$ networks. The following interactions took place:

Student-to-teacher interaction: Teacher posted the task (question) on MOBILect to prompt the students to engage with MOBILect. The following question was posted on MOBILect by the Teacher: What is the problem that this lesson is trying to solve?

Student-to-content interaction: Students watched the vodcast on MOBILect and then posted comments to answer the question (see figure $4 \mathrm{a} \& 4 \mathrm{~b}$ ).

Student-to-student interaction: students viewed other students' answers/comments (see figure 5) and then posted another set of answers/comments based on other students' comments.

Student-to-teacher interaction: Teacher viewed the entire comments posted on MOBILect by students to check for any misconception. Teacher posted some interactive comments to the students. Five different mo-

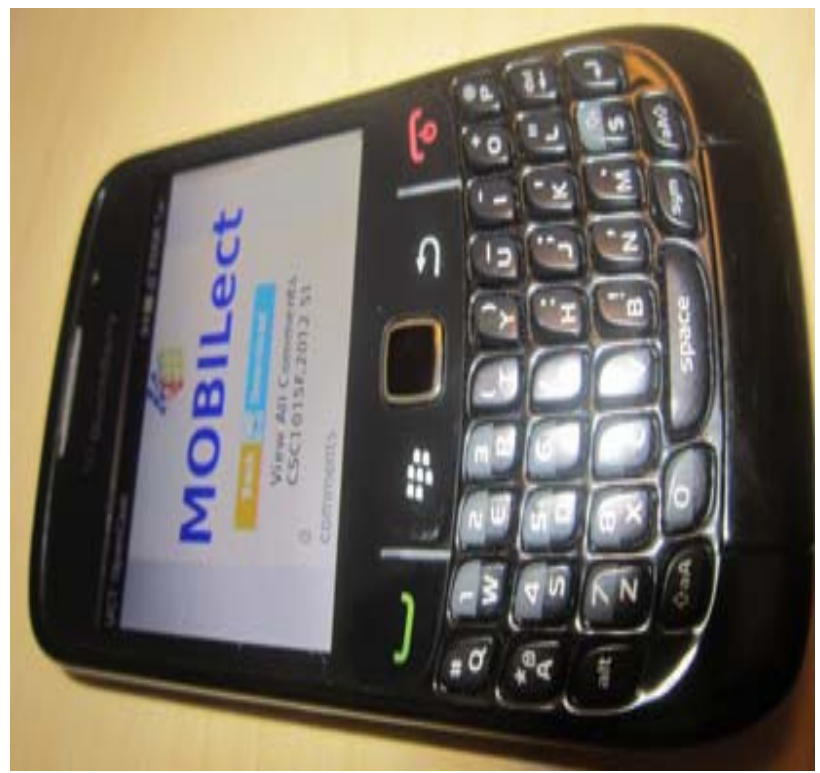

a) MOBILect on Blackberry 8520

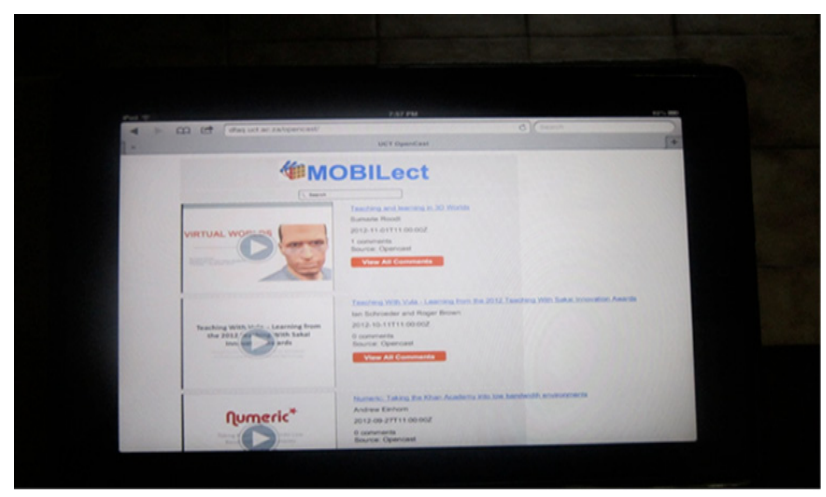

b) MOBILect on iPad

Figure 4.

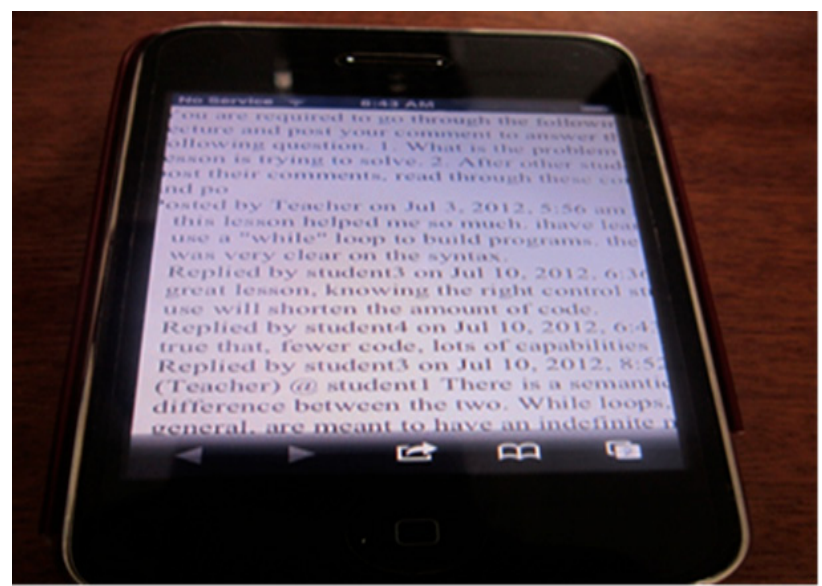

Figure 5. Some comments posted during Case study on iPhone 3G

bile devices: iPad, Samsung Galaxy S, Blackberry Curve8520, Sony Ericsson Xperia X10 and iPhone 3G were used by the students during the evaluation.

\section{Analysis of Student Comments}

In the Case Study; students and teachers interact using three types of interactions: Student-to-Content Interaction, 
Student-to-Student Interaction and Student-to-Teacher Interaction (see figure 6)

The teacher posted question to prompt and motivate the students:

What is the problem that this lesson is trying to solve?

Student-to-Content Interaction: This interaction shows some comments posted by students to answer the question:

Posted by student\#3: This lesson helped me so much; I have learnt hw to use a "while" loop to build programs. The teacher was very clear on the syntax.

Posted by student\#4: Great lesson, knowing the right control structure to use will shorten the amount of code

Posted by Student\#3: True that, fewer codes, lots of capabilities

Posted by Student \#2: The lesson makes it clear how a while loop is used comparing it with the if statement.

Posted by Student\#5: I have not been posting comments on the platform but I have constantly viewed other people's comments and this has helped me much.

Students interacted with lecture vodcast by posting their comments i.e. Student\#3 indicated that the lesson has helped her so much. She stated "I have learnt how to use a "while' loop to build programs." Student\#4 indicated that it was a great lesson and knowing the right control structure will shorten the amount of code to be written. These showed students' high-level interactions with the lecture vodcast.

Student-to-Student Interaction: In this interaction students read the comments of others and reply based on other students' comments:

Posted by student\#1: So which one is the best loop to use between the two or under what circumstances can I use the while loop?

Reply@student\#1: Something like one is for count controlled and the other when you don't know the number of iterations. (Posted by student4; Student4 replies student1)

Posted by student\#1: Thank you so much for the lesson, I really understood the concept of the while loop.

Students interacted with each other i.e. Student\#1 asked a question "So which one is the best loop to use between the two or under what circumstances can I use the while loop? Student\#4 replied "something like one is for count controlled and the other when you don't know the number of iterations." These interactions showed how students engaged in high-level interactions with each other.

Student-to-Teacher Interaction: In this interaction teacher responded to student comments.

Reply@student\#1: There is a semantic difference between the two. While loops, in general, are meant to have an indefinite number of iterations and for loops should have a more definite number of iterations. (Posted by teacher).

Posted by Teacher: Hi all, your feedback shows that some have been able to grasp the concepts. From the example given, try to write a program that prints the numbers in reverse order.

Posted by Teacher: I can see that this platform enhances learning and helps others who do not always contribute on face-to-face to also contribute, the comments helped other students focus more on the most important concepts.
Teacher interacted with students' comments i.e. Student\#1 asked a question "So which one is the best loop to use between the two or under what circumstances can I use the while loop? Teacher replied "There is a semantic difference between the two. While loops, in general, are meant to have an indefinite number of iterations and for loops should have a more definite number of iterations". This showed student-to-teacher interactions.

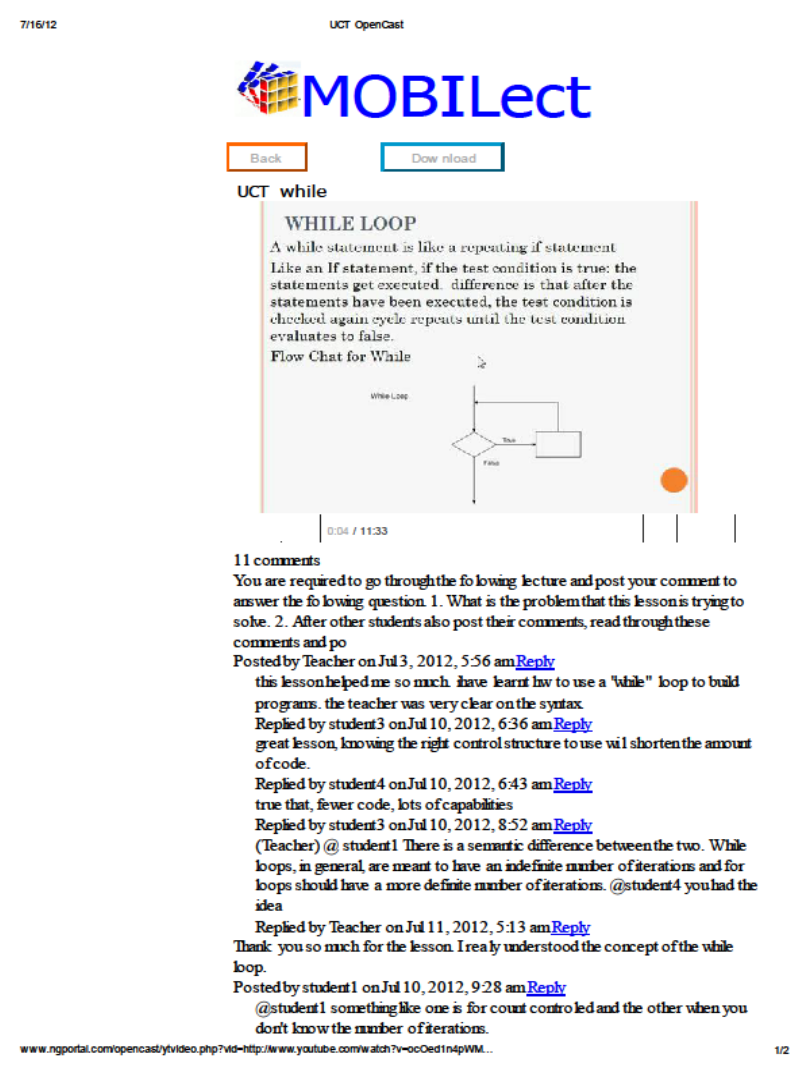

Figure 6. Comments posted by students to MOBILect

From the interactions that occur in the above case study, 11 comments were posted ( see figure 6). Of these 5 comments were posted as student watched the lecture vodcast, which suggests student-to-content interactions. 3 comments were posted in response to postings made by other students (student-to-student interactions). 3 comments were posted by teacher in response to postings made by students (student-to-teacher interactions). Based on Anderson (2003) that deep and meaningful learning is supported as long as one of the three forms of interaction (student-to-teacher; student-to-student; student-to-content) is engaged at a high-level. Students engaged with lecture vodcast at a high-level as evidenced in the 5 "comments" posted. Students engaged at a high-level with each other as evidenced in the 3 "replies" to peers' postings. Teacher also engaged at a high-level with students as evidenced in the 3 "replies" to student postings. Hence deep and meaningful learning has been achieved.

\section{E. Analysis of Open-Ended Responses}

The five Participants were asked to answer five openended questions based on MOBLEC model [3] (see figure 7). 


\section{Open-Ended Questions}

Student Matric No:

Name and type of Mobile Device

Mother Tongue (Home Language):

Gender:

Name of Course being evaluated:

Questions:

Device Usability (AB) of the MOBLEC model.

1. What are your experiences in using this tool on your own mobile device and what are the limitations posed by your mobile device

Learning Engagement intersection (BC) of the MOBLEC model.

2. How would you describe your learning experience and how would you describe the benefits you derived from using this tool?

3. How would you describe what you learnt from other students?

Interaction Technology intersection (AC) of the MOBLEC model.

4. How is the interaction with the lecturer through this tool different from f2f lecture?

5. Comment on the functionality of the tool, did it work for the purpose for which it was designed and how would you recommend this tool be improved?

Figure 7. Open-Ended questions

After the data was compiled and organised into a Microsoft word document, open coding was performed. All responses were double-coded by the researcher to ensure reliability [6]. Three apriori codes that emerged were derived from MOBLEC model; Device Usability, Learning Engagement and Interaction Technology. The Table I presents the definition of each code.

Table II provides some examples of the responses from the participants.

The first code "device usability" has four responses out of five indicating ease of access of the tool on their mobile devices. This may indicate that the tool was easy and simple to access on their mobile devices. The fifth response indicated a hindrance due to network speed and not because of the device. She reported that the $3 \mathrm{G}$ connection offered by her service provider was a bit slow, so streaming took a bit of time, but once the video clip was streamed it was ok.

The second code "Learning Engagement" has to do with the benefits of interacting with other students and teacher. All the responses reported benefits of the interaction. This may indicate the usefulness of the tool in engaging students in high-level interactions.

The 3rd code "Interaction Technology" has to do with the simplicity and functionality of the MOBILect tool. All responses agreed to the usefulness of the tool. This may indicate the tool as being very beneficial and suitable for students especially in different geographical locations (distance learning).

\section{CONCLUSION}

An Interactive Mobile Lecturing Tool "MOBILect" was able to foster deep learning among students geographically separated from their teacher. Students interacted with lecture vodcasts on their mobile devices to foster deep learning. In this paper we have been able to affirm the usefulness of MOBILect, a mobile lecturing tool in enhancing students' engagement with lecture vodcasts through mobile lecturing to promote deep learning. This tool successfully ran on five different mobile devices. MOBILect was successfully evaluated at Bindura University of Science Education, Zimbabwe in scenarios where students were separated by distance from their teacher. MOBILect is a good supplement to the traditional face-to-face lectures and can also be indispensable to other higher education institutions in developing countries of Africa.

TABLE I.

OPEN-ENDED CODES

\begin{tabular}{|l|l|}
\hline \multicolumn{1}{|c|}{ Code } & \multicolumn{1}{c|}{ Definition } \\
\hline Device Usability & $\begin{array}{l}\text { Respondent comments positively on the } \\
\text { ease of use of his/ her mobile device. }\end{array}$ \\
\hline Learning Engagement & $\begin{array}{l}\text { Respondent comments on how easy it } \\
\text { was to interact with others and gain more } \\
\text { insight into the lecture. }\end{array}$ \\
\hline Interaction Technology & $\begin{array}{l}\text { Respondent comments on how easy it } \\
\text { was to interact with the interaction tool } \\
\text { (MOBILect) }\end{array}$ \\
\hline
\end{tabular}

TABLE II.

OPEN-ENDED CODING EXAMPLES

\begin{tabular}{|c|c|}
\hline Code & Some Examples of Comments \\
\hline Device Usability & $\begin{array}{l}\text { "It was suitable. The video was very } \\
\text { clear and the internet access is super" } \\
\text { "I think it is a better and more efficient } \\
\text { way of studying and learning. Since most } \\
\text { of us students are used to mobile } \\
\text { browsing, chat and online interaction" } \\
\text { Participants commented positively on } \\
\text { the ease of use of his/ her mobile device. }\end{array}$ \\
\hline Learning Engagement & $\begin{array}{l}\text { "I have learnt and understood the defer- } \\
\text { ence of a "while loop" and a "for loop" } \\
\text { and I can now confidently pick the cor- } \\
\text { rect control structure to solve a prob- } \\
\text { lem" } \\
\text { "It was great and educative. Interaction } \\
\text { with peers were sincere with no timidi- } \\
\text { ty" } \\
\text { Participants commented on how easy it } \\
\text { was to interact with others and gain more } \\
\text { insight into the f } 2 \text { f lecture. }\end{array}$ \\
\hline Interaction Technology & $\begin{array}{l}\text { "MOBILect was very easy in that instead } \\
\text { of me going through some text I had to } \\
\text { just see the code in action. It was very } \\
\text { useful in the sense that I didn't have to } \\
\text { make a trip to the library or the lecture } \\
\text { room but had to view it from the comfort } \\
\text { of my bed, making it cost effective. It } \\
\text { was intuitive in that I could replay the } \\
\text { video over and over, plus the addition of } \\
\text { interactivity in the comments part with } \\
\text { other students regardless of geograph- } \\
\text { ical location" } \\
\text { Participants commented on how easy it } \\
\text { was to interact with the interaction tool } \\
\text { (MOBILect). }\end{array}$ \\
\hline
\end{tabular}




\section{REFERENCES}

[1] T. Anderson, Modes of interaction in distance education: Recent developments and research questions. In D. M. Moore (Ed.), Handbook of Distance Education, 2003 (pp. 129-144) Mahwah, NJ: Erlbaum

[2] D. Becking, S. Betermieux, B. Bomsdorf, B. Feldmann, E.Heuel, P. Langer, G. Schlageter, Didactic profiling:supporting the mobile learner. In: World Conference on Elearningin Corporate, Government, Health and HigherEducation. Association for the Advancement of Computers in Education, pp. 1760-1767, 2004.

[3] O. Boyinbode, D. Ng'ambi, and A. Bagula, "An Interactive Mobile Lecturing Model: Enhancing Student Engagement with FaceTo-Face Sessions" International Journal of Mobile and Blended Learning, 3(2), 1-21, April-June 2013 http://dx.doi.org/ 10.4018/jmbl.2013040101

[4] Cam studio. Cam Studio 2.5. Retrieved June 10, 2012, from http://www.winportal.com/camstudio

[5] S. Cheng, W.Hwang, S.Wu, R. Shadiev and C. Xie, A mobile device and online system with contextual familiarity and its effects on English learning on campus. Educational Technology \& Society, 13(3), 93-109, 2010

[6] W. Gibson, and A. Brown, Working with qualitative data. SAGE Publications London, 2009

[7] M.J.W. Lee and A.Chan, Pervasive, lifestyle-integrated mobile learning for distance learners: an analysis and unexpected results from a podcasting study, Open Learning: The Journal of Open and Distance Learning, Vol. 22, Issue 3, pp. $201-218,2007$

[8] O. McGarr, A review of podcasting in higher education: Its influence on the traditional lecture. Australasian Journal of Educational Technology, 25(3), 309-321, 2009

[9] O’Malley, C., G. Vavoula, J. Glew, J. Taylor, M. Sharples, and P. Lefrere. Guidelines for learning/teaching/tutoring in a mobile environment Ricerca, Italy: MOBIlearn2003/Giunti Retrieved June
12, 2012 from http://www.mobilearn.org/download/results/ guidelines.pdf

[10] M. Sharples, A. Sanchez, M. Milrad, and G. Vavoula, Mobile learning: Small devices, big issues. In N. Balacheff, S. Ludvigsen, T. de Jong, A. Lazonder \& S.Barnes (Eds.), Technology enhanced learning: Principles and products (pp. 233-249). Heidelberg, Germany: Springer, 2008

[11] Warburton, 'Deep learning and education for sustainability', International Journal of Sustainability in Higher Education 4(1), 4456, 2003 http://dx.doi.org/10.1108/14676370310455332

\section{AUTHORS}

O. Boyinbode, $\mathrm{PhD}$, is a recent doctoral graduate from the Department of Computer Science's ICT4D research group the University of Cape Town, South Africa. She is a lecturer in the Computer Science Department at the Federal University of Technology, Akure, Nigeria. Her research interests are in Mobile Learning, Ubiquitous Learning and Mobile Networks. She is a professional member of ACM and IEEE.

D. Ng'ambi, PhD, is an Associate Professor and a leading researcher in mobile learning in resource constrained environments. He works for the Centre of Educational Technology at the University Of Cape Town (UCT). He is currently the Coordinator of a postgraduate programme in educational technology, and a convener of a doctoral programme in the School of Education at the University of Cape Town, South Africa.

Submitted 11 September 2013. Published as re-submitted by the authors 12 October 2013. 